This is a self-archiving document (manuscript version):

The reasons for the high power density of fuel cells fabricated with directly deposited membranes

By: Vierrath, Severin; Breitwieser, Matthias; Klingele, Matthias; Britton, Benjamin; Holdcroft, Steven; Zengerle, Roland; Thiele, Simon

Published in: Journal of Power Sources

Volume 326, 15 September 2016, Pages 170-175 (Please be aware:

Page numbering in this manuscript can be different to published version!)

Publisher: Elsevier | Year: 2016

DOI: 10.1016/j.jpowsour.2016.06.132

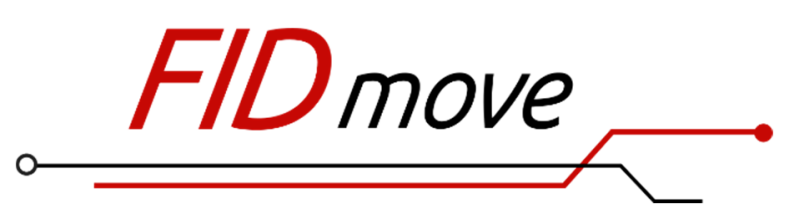

Brought to you by the Scientific Information Service for Mobility and Transport Research

Fachinformationsdienst Mobilitäts- und Verkehrsforschung

Website: www.fid-move.de

Repository: publish.fid-move.de

Contact: publish@fid-move.de

(C) 2020. This manuscript version is made available under the CC-BYNC-ND 4.0 license.

http://creativecommons.org/licenses/by-nc-nd/4.0/ 


\title{
The reasons for the high power density of fuel cells fabricated with directly deposited membranes
}

\author{
Severin Vierrath ${ }^{\mathrm{a}}$, Matthias Breitwieser ${ }^{\mathrm{a}, \mathrm{b}}$, Matthias Klingele ${ }^{\mathrm{a}}$, Benjamin Britton ${ }^{\mathrm{c}}$, \\ Steven Holdcroft ${ }^{c}$, Roland Zengerle ${ }^{\text {a, b }}$, Simon Thiele ${ }^{\text {a, b, d, * }}$ \\ a Laboratory for MEMS Applications, IMTEK Department of Microsystems Engineering, University of Freiburg, Georges-Koehler-Allee 103, 79110 Freiburg, \\ Germany \\ ${ }^{\mathrm{b}}$ Hahn-Schickard, Wilhelm-Schickard-Straße 10, 78052 Villingen-Schwenningen, Germany

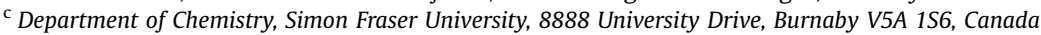 \\ ${ }^{\mathrm{d}}$ FIT, University of Freiburg, Georges-Koehler-Allee 105, 79110 Freiburg, Germany
}

\section{A B S T R A C T}

In a previous study, we reported that polymer electrolyte fuel cells prepared by direct membrane deposition (DMD) produced power densities in excess of $4 \mathrm{~W} / \mathrm{cm}^{2}$. In this study, the underlying origins that give rise to these high power densities are investigated and reported. The membranes of high power, DMD-fabricated fuel cells are relatively thin $(12 \mu \mathrm{m})$ compared to typical benchmark, commercially available membranes. Electrochemical impedance spectroscopy, at high current densities $\left(2.2 \mathrm{~A} / \mathrm{cm}^{2}\right)$ reveals that mass transport resistance was half that of reference, catalyst-coated-membranes (CCM). This is attributed to an improved oxygen supply in the cathode catalyst layer by way of a reduced propensity of flooding, and which is facilitated by an enhancement in the back diffusion of water from cathode to anode through the thin directly deposited membrane. DMD-fabricated membrane-electrode-assemblies possess $50 \%$ reduction in ionic resistance $\left(15 \mathrm{~m} \Omega \mathrm{cm}^{2}\right)$ compared to conventional CCMs, with contributions of $9 \mathrm{~m} \Omega \mathrm{cm}^{2}$ for the membrane resistance and $6 \mathrm{~m} \Omega \mathrm{cm}^{2}$ for the contact resistance of the membrane and catalyst layer ionomer. The improved mass transport is responsible for $90 \%$ of the increase in power density of the DMD fuel cell, while the reduced ionic resistance accounts for a $10 \%$ of the improvement.

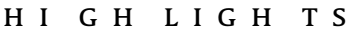

- Origin of high power density of DMD fuel cells examined in 5 separate experiments.

- Extensive EIS study shows: high power density due to enhanced water management.

- DMD fuel cells have very thin $(12 \mu \mathrm{m})$ membranes facilitating water diffusion.

- DMD enables low ionic resistance of membrane and membranelelectrode interface.

\section{Introduction}

In a recent publication, Klingele et al. reported power densities of $4 \mathrm{~W} / \mathrm{cm}^{2}$ (with $300 \mathrm{kPa}$ oxygen) for polymer electrolyte fuel cells prepared using direct membrane deposition (DMD) [1]. In the DMD approach, the conventional catalyst coated membrane (CCM) is

replaced by two gas diffusion electrodes (GDE) coated with ionomer solution via inkjet printing. This technique was used by Breitwieser et al. to increase the Pt-utilization of low-loaded electrodes to $88 \mathrm{~kW} / \mathrm{g} \mathrm{Pt} \mathrm{[2]} \mathrm{and} \mathrm{by} \mathrm{Wehkamp} \mathrm{et} \mathrm{al.} \mathrm{to} \mathrm{improve} \mathrm{power}$ densities of medium temperature fuel cells [3]. The precise reasons for the higher peak power density were not resolved at that time, however, the fundamental reason(s) for the observed high power densities is essential to elucidate in order to further improve the DMD method, and is therefore the central motivation of this work.

Modeling can be used to deconvolute the reasons for the enhanced performance of DMD fuel cells [4]. Fig. 1 depicts a

* Corresponding author. Laboratory for MEMS Applications, IMTEK Department of Microsystems Engineering, University of Freiburg, Georges-Koehler-Allee 103, 79110 Freiburg, Germany.

E-mail address: simon.thiele@imtek.de (S. Thiele).

Keywords:

PEM fuel cel

Direct membrane deposition

Membrane

Nafion

Droplet-on-demand

Catalyst-coated-membrane

Membrane-electrode-assembly 


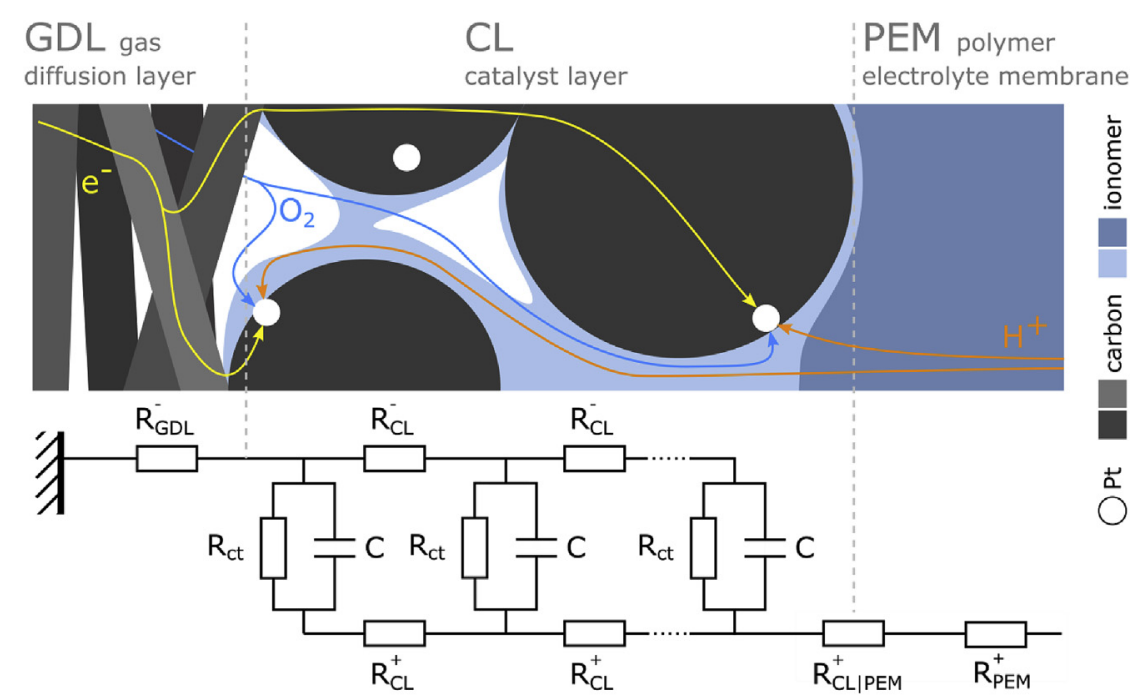

Fig. 1. Schematic of the cathode side of a fuel cell and equivalent circuit

schematic of the cathode side of the DMD fuel cell, comprising the gas diffusion layer (GDL), the catalyst layer $(\mathrm{CL})$ and the polymer electrolyte membrane (PEM). The equivalent circuit represents the resistances of electron or proton conduction and the transmissionline resistance-capacitor network for the catalytic sites in the porous electrode [5-7]. This simplistic representation is commonly used to interpret fuel cell impedance data [8,9]. During fuel cell operation, electron current is conducted through the carbon phase (yellow path), and is subject to electric resistances, $R_{G D L}^{-}$and $R_{C L}^{-}$, in order to reach the catalytic sites (white spheres). The ionic resistances, $R^{+}$, represent protons conducted (orange path) through the membrane $\left(R_{P E M}^{+}\right)$, through the membrane|catalyst layer ionomer $\left(R_{P E M \mid C L}^{+}\right)$interface, as well as through the catalyst layer ionomer $\left(R_{C L}^{+}\right)$. The catalytic sites are represented by a capacitor and the charge transfer resistance $R_{c t}$ in parallel. A reduction in these resistances and an increase in the number of catalytically active sites are potential reasons for the higher power density of the DMD fuel cell compared to conventional CCM- or GDE-based fuel cells. The electric resistances, however, are unaffected by the membrane deposition process and were therefore not investigated. In the following, the number of catalytic sites and all cell polarizing resistances of a DMD fuel cell were compared to the respective values of conventional fuel cells with CCMs or GDEs prepared with Nafion membranes, each with the same $\mathrm{Pt} / \mathrm{C}$ and Nafion loading. By comparing the DMD fuel cells to fuel cells with Nafion-based CCMs and GDEs, the reasons for the increased power density of DMD fuel cells were elucidated.

\section{Methods}

Direct membrane deposition was carried out as described in the work of Klingele et al. [1]. For the investigation of the membrane resistance, the membrane|catalyst layer interface resistance and the electrochemically active surface area, substrate GDEs and $5 \mathrm{~cm}^{2}$ commercial reference CCMs (Paxitech SAS) with $0.5 \mathrm{mg} \mathrm{Pt} \mathrm{cm}{ }^{-2}$ (anode/cathode) and 70\% Pt/C were used. All other investigations were conducted with $0.1 \mathrm{mg} \mathrm{Pt} \mathrm{cm}{ }^{-2}$ loaded GDEs (anode/cathode) and CCMs fabricated as described in Ref. [2]. The DMD fuel cells were assembled using a PVDF sub-gasket (Novofoil) with a $2 \times 2 \mathrm{~cm}^{2}$ opening to seal the edges of the $5 \mathrm{~cm}^{2}$ GDEs. This resulted in an active fuel cell area of $4 \mathrm{~cm}^{2}$ due to the dimensions of the subgaskets. Potential artifacts caused by a reduction of the active area 
were examined by fabricating DMD fuel cells with different subgasket opening dimensions. As can be seen in Fig. S1 in the supplementary material, the three examined fuel cells $\left(4 \mathrm{~cm}^{2}, 2.25 \mathrm{~cm}^{2}\right.$ and $1 \mathrm{~cm}^{2}$ active area) assembled with identical $5 \mathrm{~cm}^{2}$ GDEs varied linearly according to active area in terms of polarization data and ionic resistance.

The thicknesses of the directly deposited membranes were measured according to the following procedure: Firstly, crosssections were obtained by cryo-fracturing the MEA in liquid nitrogen. In the next step, several $\mathrm{mm}$ of the cross-section were imaged (Phenom Pro SEM, $10 \mathrm{kV}$ accelerating voltage) and photostitched. The high Z-contrast in SEM between membrane and catalyst layer allowed automatizing the thickness measurement by image processing in Matlab using a threshold and a distance transform. The presented thickness distribution is based on $7.2 \mathrm{~mm}$ of imaged membrane cross-section and approximately 20.000 measured thicknesses.

A Scribner 850e system was used for fuel cell characterization. High frequency resistance was measured by a frequency-response analyzer at an $\mathrm{AC}$ frequency of $3.2 \mathrm{kHz}$, a current density of $0.5 \mathrm{~A} \mathrm{~cm}^{-2}, 80{ }^{\circ} \mathrm{C}, \mathrm{H}_{2}$ /air and 1.5/2.5 stoichiometric flow, $90 \%$ relative humidity and ambient pressure. The high relative humidity prevents the membranes, especially the thicker references, from drying out. In contrast to that, $\mathrm{H}_{2} / \mathrm{N}_{2}$ Impedance was performed (PAR VersaStat 4) after equilibration to a steady potential after $\sim 1 \mathrm{~h}$ under $\mathrm{H} 2 / \mathrm{N} 20.25 / 0.25$ slpm fixed flow at $80^{\circ} \mathrm{C}$, ambient pressure and low relative humidity of $50 \%$ in order to increase catalyst layer ionic resistance to measurable values. A bias of $0.45 \mathrm{~V}$ was applied, with a $10 \mathrm{mV}$ AC variation scanned from $0.1 \mathrm{~Hz}$ to $100 \mathrm{kHz}$. The linear sweep and cyclic voltammetry was conducted at $80^{\circ}$, ambient pressure, relative humidity of $100 \%$ and low fixed flow of $\mathrm{H}_{2} / \mathrm{N}_{2} \quad 0.2 / 0.05 \mathrm{l} / \mathrm{min}$ in order to prevent artifacts [10]. The electrochemically active surface area (ECSA) was calculated as follows: Cyclic voltammograms of three DMD and two reference GDEs with NR-211 membranes using 8 cycles per sample were corrected for electrical shorting with the slope of the respective linear sweep voltammograms, and the resultant $\mathrm{H} 2$ adsorption and desorption current densities were integrated and averaged to calculate the ECSA $[7,10] . \mathrm{H}_{2} / \mathrm{O}_{2}$ impedance data was recorded at $80{ }^{\circ} \mathrm{C}, \mathrm{H}_{2} / \mathrm{O}_{2}$ $0.25 / 0.5 \mathrm{l} / \mathrm{min}$ fixed flow, ambient pressure and 90\% $\mathrm{RH}$ from $10 \mathrm{kHz}$ to $0.1 \mathrm{~Hz}$ with an AC perturbation of 5\% using the Scribner built-in frequency response analyzer. The polarization curves were 
recorded at $80^{\circ} \mathrm{C}, \mathrm{H}_{2} / \mathrm{O}_{2} 0.25 / 0.5 \mathrm{l} / \mathrm{min}$ fixed flow, ambient pressure and $90 \% \mathrm{RH}$ with current steps from OCV to $0.3 \mathrm{~V}$ at $2 \mathrm{~A}$ intervals (CCM reference) and $1 \mathrm{~A}$ intervals (DMD and GDE) holding the current for $5 \mathrm{~min}$ per point, and additional $0.05 \mathrm{~A}$ intervals to resolve the kinetic region.

\section{Results}

\subsection{Membrane resistance $\boldsymbol{R}_{\mathbf{P E M}}^{+}$}

The membrane resistance can be expressed as $R_{P E M}^{+}=\delta / \sigma$, with $\delta$ being the thickness of the membrane and $\sigma$ being its intrinsic conductivity. Firstly, the thickness was investigated by imaging cryo-fractured cross-sections by SEM. A sample cross-section and the resulting distribution of thicknesses are depicted in Fig. 2. The fitted Gaussian distribution yields a thickness of $11.9 \pm 1.2 \mu \mathrm{m}$ of the deposited membrane, which is substantially thinner than commercially available membranes, such as Nafion NR-211 $(25 \mu \mathrm{m})$ [11] or Nafion HP $(20 \mu \mathrm{m})$. The reduced thickness consequently yields a lower membrane resistance, $R_{P E M}^{+}$.

The intrinsic conductivity corresponds to the reciprocal membrane resistance per thickness and can therefore be determined by measuring the resistances of differently thick membranes $[12,13]$. The thickness of the directly deposited membranes was varied by depositing 1 to 4 layers of ionomer dispersion on the GDEs resulting in total membrane thicknesses of $12,20,33$ and $48 \mu \mathrm{m}$. As references, the thinnest commercially available membranes were chosen: Nafion HP $(20 \mu \mathrm{m}), \mathrm{NR}-211(25 \mu \mathrm{m})$ and N-112 $(50 \mu \mathrm{m})$. The high frequency resistance (HFR) plotted over the thickness of each cell is shown in Fig. 3 along with the least-square fitted slopes (dotted lines). One can observe, that the HFR-evolution over membrane thickness of the DMD fuel cells $(0.14 \mathrm{~S} / \mathrm{cm})$ and the reference $(0.15 \mathrm{~S} / \mathrm{cm})$ show comparable slopes and therefore intrinsic conductivities, which are also comparable to literature values for Nafion [11]. Hence, ionic conductivity of the membrane itself is not a reason for better fuel cell performance of DMD fuel cells, whereas the $50 \%$ reduced thickness causes a lower membrane resistance $R_{P E M}^{+}$and can lead to better fuel cell performance.

\subsection{Resistance of the PEM-CL interface $\boldsymbol{R}_{\mathbf{P E M} \mid \mathbf{C L}}^{+}$}

The resistance of the membrane|catalyst layer interface, $R_{P E M \mid C L}^{+}$, can be evaluated by extrapolating the HFR (Fig. 3) to zero

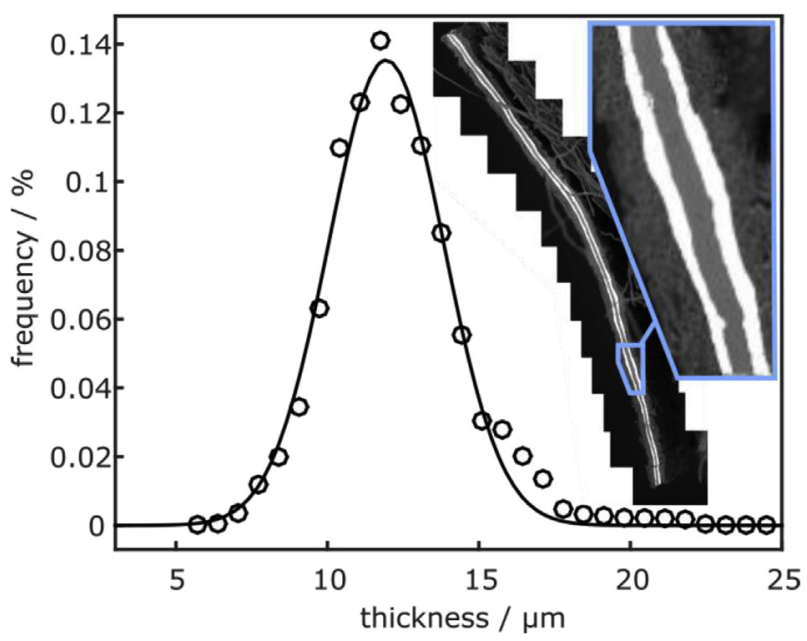

Fig. 2. Distribution of measured thicknesses of a direct deposited membrane and a $7 \mathrm{~mm}$ cross-section of the cryo-fractured DMD fuel cell. 


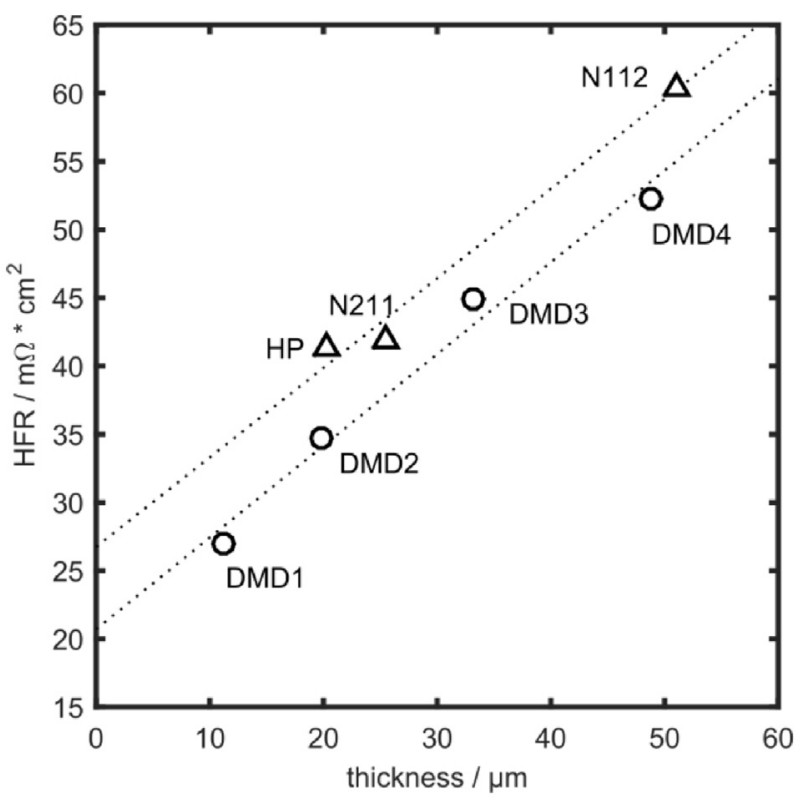

Fig. 3. High frequency resistances measured at $0.5 \mathrm{~A} \mathrm{~cm}^{-2}$ and $3.2 \mathrm{kHz}$ vs. thickness for DMD fuel cells with 1-4 layers of Nafion coating and reference CCMs. Operation conditions were: $\mathrm{H}_{2}$ /air 1.5/2.5 stoichiometric flow, $80{ }^{\circ} \mathrm{C}, 90 \% \mathrm{RH}$, ambient pressure. Linear fits (dotted lines) were obtained by the least squares method.

membrane thickness and thus removing the membrane resistance $R_{P E M}^{+}[14,15]$. In the equivalent circuit (Fig. 1) one can see that the HFR also contains electrical resistances (at high frequencies the current is conducted through the shorted capacitor, which is the closest to the membrane). For the DMD sample, after subtracting the electric resistances $\left(11.3 \pm 0.3 \mathrm{~m} \Omega \mathrm{cm}^{2}\right.$, as determined by Klingele et al. [1]) an interfacial resistance $R_{P E M \mid C L}^{+}$of $10 \mathrm{~m} \Omega \mathrm{cm}^{2}$ remains, which is $40 \%$ lower than that of the reference CCM fuel cells $\left(16 \mathrm{~m} \Omega \mathrm{cm}^{2}\right)$. However, one must consider that this value is subject to several potential sources of error, including potential errors in linear regressions $\left(\mathrm{R}^{2}\right.$ of 0.9727 for the DMD fuel cell and 0.9766 for the references), the different equivalent weights of the reference membranes, or the unknown impact of the reinforcement on Nafion HP's resistance, $R_{P E M}^{+}$. Nevertheless, the DMD fuel cells possess a systematically lower resistance for the same thickness, indicating a lower membrane|catalyst layer interface resistance. Furthermore, this decreased interfacial resistance is plausible when considering that during the membrane deposition, the ionomer dispersion partially infiltrates the catalyst layer. In the SEM images of the membrane|catalyst layer interface (Fig. 4) a few hundred nm of catalyst layer can be observed to be infiltrated by the ionomer during membrane deposition. This potentially results in a higher interfacial contact area of membrane and ionomer, and lower contact resistance.

\subsection{Catalyst layer ionic resistance $\boldsymbol{R}_{C L}^{+}$}

In order to estimate the ionic resistance in the catalyst layer, $R_{C L}^{+}$, electrochemical impedance spectroscopy (EIS) with the cathode fed with nitrogen was used $[6,16,17]$. Since no reaction can take place, only the ohmic resistances and the capacitances remain in the equivalent circuit (as shown in Ref. [6]), which allows assessing the ionic resistance of the catalyst layer. Fig. 5 shows the impedance spectra of a DMD fuel cell and two Nafion NR-211 reference fuel cells, one prepared with a CCM and the other with GDEs and a membrane foil. The real part of the $45^{\circ}$-slope at high frequencies, as marked below the real axis, corresponds to a third of $R_{C L}^{+}[5,6]$. 


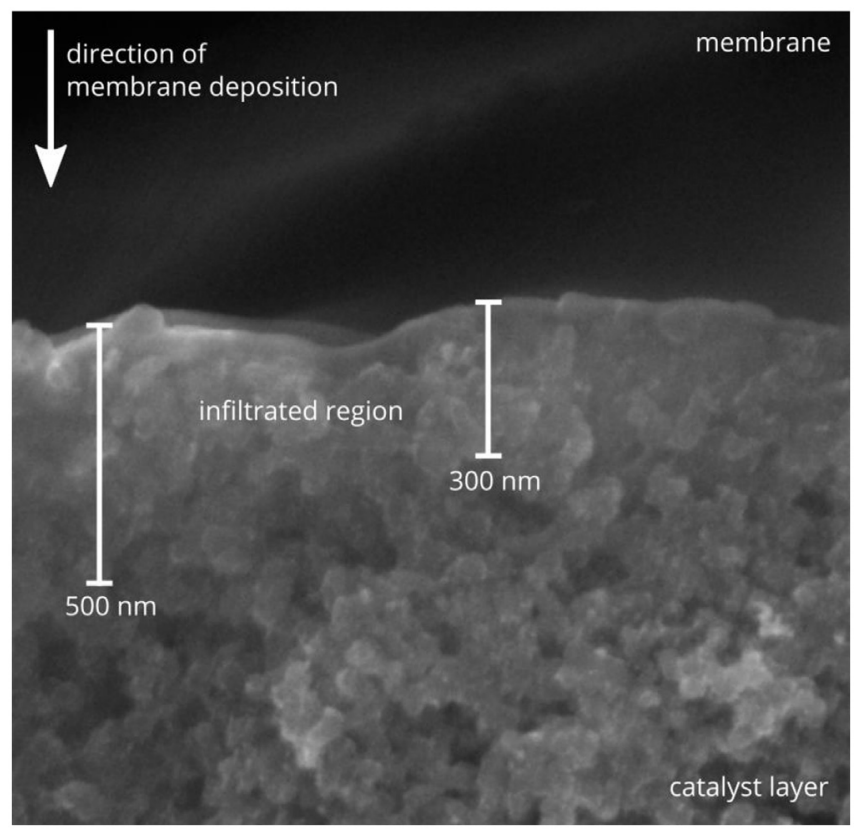

Fig. 4. SEM image of the membrane|catalyst layer-interface of a cryo-fractured DMD at $10 \mathrm{kV}$. The catalyst layer appears to possess no dark pores within a few hundred nm close to the membrane, indicating that this region is infiltrated with ionomer during the membrane deposition.

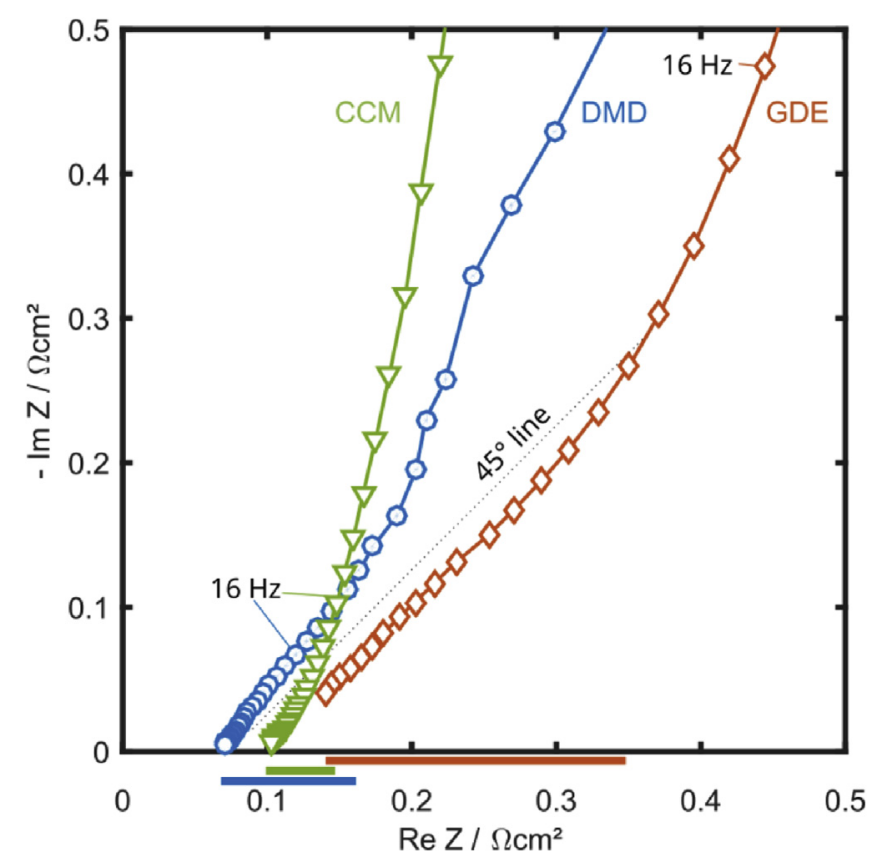

Fig. 5. $\mathrm{H}_{2} / \mathrm{N}_{2}$-Impedance spectra of a DMD fuel cell and two references (CCM and GDE). The real part of the $45^{\circ}$-slope at high frequencies (also marked below the real axis) corresponds to a third of the ionic resistance of the catalyst layer. Operation conditions were $\mathrm{H}_{2} / \mathrm{N}_{2} 0.25 / 0.25$ slpm fixed flow, $80{ }^{\circ} \mathrm{C}, 50 \% \mathrm{RH}$, ambient pressure.

Spectra reveal that the DMD fuel cell possesses a 2 times lower $R_{f L}^{+}$ $\left(0.28 \Omega \mathrm{cm}^{2}\right)$, compared to the GDE-fabricated fuel cell $\left(0.63 \Omega \mathrm{cm}^{2}\right)$. This is explained by the fact that the ionomer infiltrates the catalyst layer during membrane deposition creating a gradually increasing ionomer content towards the membrane, which lowers the ionic resistance within the catalyst layer, as suggested by Lefebvre et al. [6]. However, the resistance of the DMD fuel cell is still higher than 
that of the CCM fuel cell $\left(0.15 \Omega \mathrm{cm}^{2}\right)$ leading to the conclusion that the ionic catalyst layer resistance $R_{C L}^{+}$is not the reason for the enhanced power density of the DMD fuel cells.

\subsection{Number of catalytically active sites}

To investigate the effect of the DMD process on the electrochemically active surface area (ECSA), cyclic voltammetry was employed (Fig. S2 - supplementary material). The identical GDEs used with a membrane foil (Nafion NR-211) served as reference. The Pt-loadings of $0.5 \mathrm{mg} / \mathrm{cm}^{2}$ anode/cathode were the same in both cases. The integration of the $\mathrm{H}_{2}$ adsorption and desorption peaks yielded ECSAs of $66 \pm 1 \mathrm{~m}^{2} \mathrm{Pt} / \mathrm{mg} \mathrm{Pt}$ (DMD) and $64 \pm 2 \mathrm{~m}^{2} \mathrm{Pt} /$ $\mathrm{mg}$ Pt (GDE). Thus, membrane deposition does not increase the ECSA and the ECSA is therefore not considered a factor in the increased fuel cell performance of DMD fuel cells.

\subsection{Charge transfer resistance, $\boldsymbol{R}_{\boldsymbol{c t}}$, and mass transport resistance $\boldsymbol{R}_{\boldsymbol{m} t}$}

Electrochemical impedance spectroscopy is a powerful tool to differentiate resistances by their typical relaxation times [9]. Typically the Nyquist plots of the impedance spectra are used to identify the high frequency intercept with the real axis, which corresponds to the HFR. The HFR includes the electrical resistance and both the membrane and membrane|catalyst layer interfacial protonic resistances [18]. The low frequency resistance (LFR) consists of the sum of the HFR and additional resistances emerging at lower frequencies, namely protonic resistance of the catalyst layer, the charge transfer resistance and resistance due to limited oxygen diffusion $[9,19]$. The difference between LFR and HFR is commonly termed charge transfer resistance. To avoid confusion, in this work we call this value low minus high frequency resistance $R_{L F-H F}$ as it strictly also contains the catalyst layer ionic resistance and the mass transport resistance. Hence, $R_{L F-H F}$ depends on kinetics $\left(R_{c t}\right.$, HFloop), ionic resistance in the catalyst layer $\left(R_{C L}^{+}, 45^{\circ}\right.$-slope at beginning of HF-loop) and mass transport ( $R_{m t}$, LF-loop) [20]. This mass transport resistance has the same impact as the charge transfer resistance in the equivalent circuit and can therefore only be identified by impedance spectroscopy. Fig. 6a depicts $R_{L F-H F}$ plotted over current densities for a DMD fuel cell and two reference fuel cells with a Nafion NR-211 membrane, one as CCM and one with GDEs. For each current density in Fig. 6a, complete impedance spectra were recorded in order to extract $R_{L F-H F}$. At low current densities $R_{L F-H F}$ is comparable for the DMD fuel cell $\left(0.50 \Omega \mathrm{cm}^{2}\right)$ and the reference cells with the CCM $\left(0.54 \Omega \mathrm{cm}^{2}\right)$ and the GDE $\left(0.52 \Omega \mathrm{cm}^{2}\right)$, as can also be observed in the spectra at $0.1 \mathrm{~A} \mathrm{~cm}-2$ (Fig. 6b). This indicates similar kinetics for all three samples, as $R_{L F-H F}$ is dominated by kinetics at low overpotentials. Comparable Tafel slopes and ECSAs (see supplementary) confirm this hypothesis [7]. Furthermore, this result meets the expectations considering that the samples possessed identically-formed catalyst layers. Hence, DMD does not improve electrode kinetics, kinetics discounted as a reason for the increased fuel cell performance.

At $0.5 \mathrm{~A} \mathrm{~cm}^{-2}$ (Fig. 6c) the spectrum of the GDE fuel cell reveals an increased $R_{C L}^{+}$, observable as a $45^{\circ}$-Warburg slope at high frequencies, in contrast to that of the DMD fuel cell. Thus, the partial infiltration of the catalyst layer during the membrane deposition process appears to improve the catalyst layer conductivity of the GDE, confirming the results from the $\mathrm{H}_{2} / \mathrm{N}_{2}$ EIS analysis.

The CCM and GDE references show a much stronger increase of $R_{L F-H F}$ with increasing current densities than the DMD fuel cell. This stronger increase can be attributed to the mass transport resistance $R_{m t}$, i.e. a limitation of the oxygen diffusion, which can be observed as a second loop at low frequencies in the spectra at 

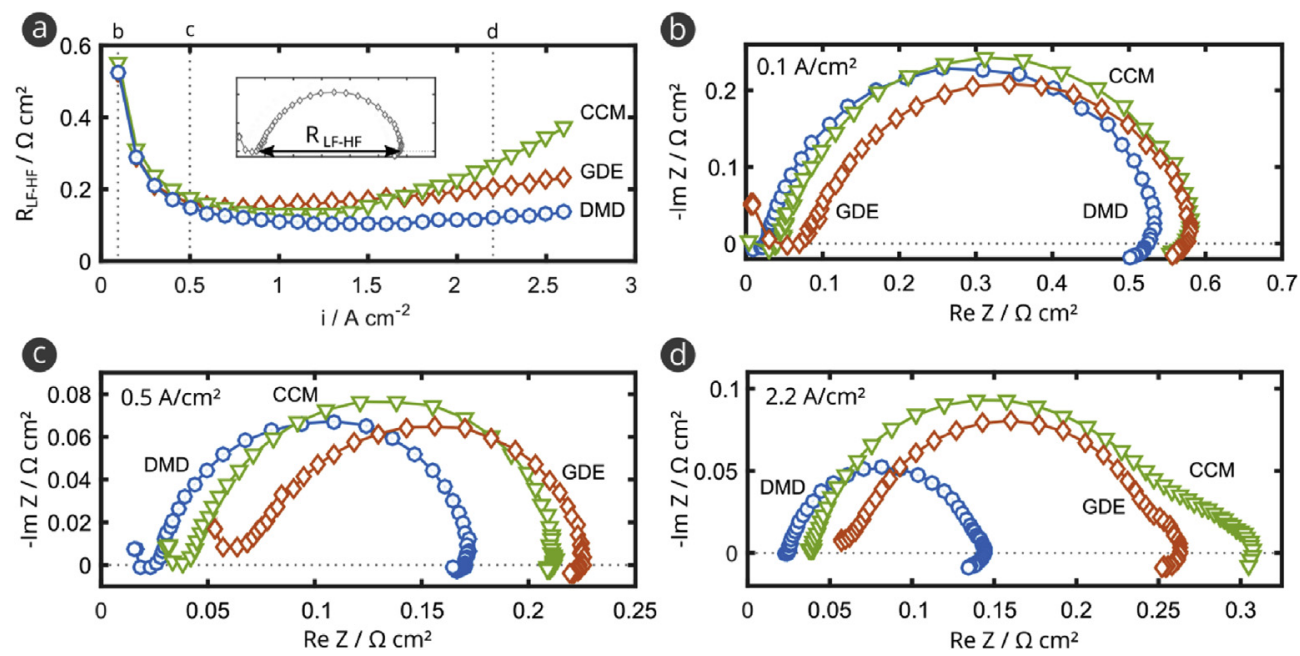

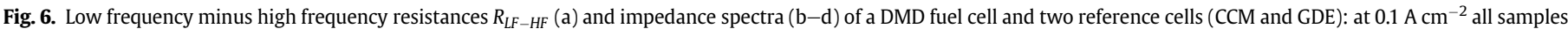

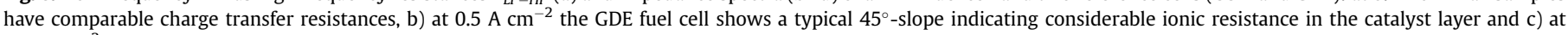

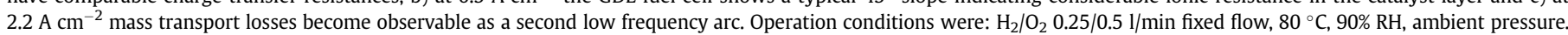

$2.2 \mathrm{~A} \mathrm{~cm}^{-2}$ (Fig. 6d). At this current density, $R_{L F-H F}$ of the DMD fuel cell $\left(0.12 \Omega \mathrm{cm}^{2}\right)$ is significantly lower than that of the GDE $\left(0.20 \Omega \mathrm{cm}^{2}\right)$ or CCM $\left(0.27 \Omega \mathrm{cm}^{2}\right)$ references. Although this second mass transport loop is not explicitly visible at spectra of lower current densities, e.g. $0.5 \mathrm{~A} \mathrm{~cm}^{-2}$ (Fig. 6b), the increase of $R_{L F-H F}$ suggest mass transport losses with onset at lower current densities, as the kinetic losses are expected to hit a steady state [20]. The absence of the second semi-circle at lower current densities could be explained by similar relaxation times of the rather sluggish oxygen reduction reaction kinetics and the oxygen diffusion, which results in the merging of the two semi-circles to one single semicircle $[21,22]$. Thus, DMD improves the mass transport resistance $R_{m t}$, which is a reason for better fuel cell performance.

This finding may be explained by an increased back-diffusion of generated water through the thin directly deposited membrane. Thicker conventional membranes cause significant amounts of water to accumulate in the cathode catalyst layer [21-27]. By consequence, the DMD fuel cell accumulates less water in the pore space of the cathode facilitating the oxygen diffusivity inside the cathode catalyst layer. Enhanced back-diffusion of water through the thin directly deposited membrane was first hypothesized in the work of Klingele et al. and was recently confirmed by an in-situ neutron radiography study of a DMD fuel cell operated at low feed gas humidification [28]. This hypothesis is further strengthened by the fact that DMD fuel cells with increasing membrane thicknesses also show increasing $R_{L F-H F}$ at high current densities as shown in Fig. S3 of the supplementary material. The relation of membrane thickness and mass transport resistance $R_{m t}$ has also been reported in impedance studies with conventional membranes $[21,25]$.

This hypothesis, however, does not explain why $R_{L F-H F}$ of the CCM reference increases stronger than that of the GDE reference (Fig. 6a). As both have the same membrane, a beneficial catalyst layer morphology of the GDE remains as potential explanation for the improved water management of both GDE-based fuel cells (GDE + membrane foil and the DMD fuel cell). Different morphologies of the catalyst layers of GDE and CCM are not unlikely considering that the spray-coating is once applied onto an ionomer membrane and, in the case of the GDE, onto a porous substrate. Another possible explanation would be a facilitated water transport through the membrane due to a higher contact area of membrane and ionomer phase of the catalyst layer as shown in Fig. 3 [29]. 
The reduced mass transport resistance $R_{m t}$ is the main reason for the DMD fuel cell's superior power density. This can be seen in the impedance spectra at $2.2 \mathrm{~A} / \mathrm{cm}^{2}$ (Fig. $6 \mathrm{~d}$ ), where the reference CCM has its maximum power density (Fig. 7). The high frequency intercepts of both spectra are in the same range, while the low frequency intercept of the CCM reference is twice as high as that of the DMD fuel cell. Comparing the resulting resistances shows that the reduction of $R_{L F-H F}$ is responsible for $90 \%$ of the DMD's
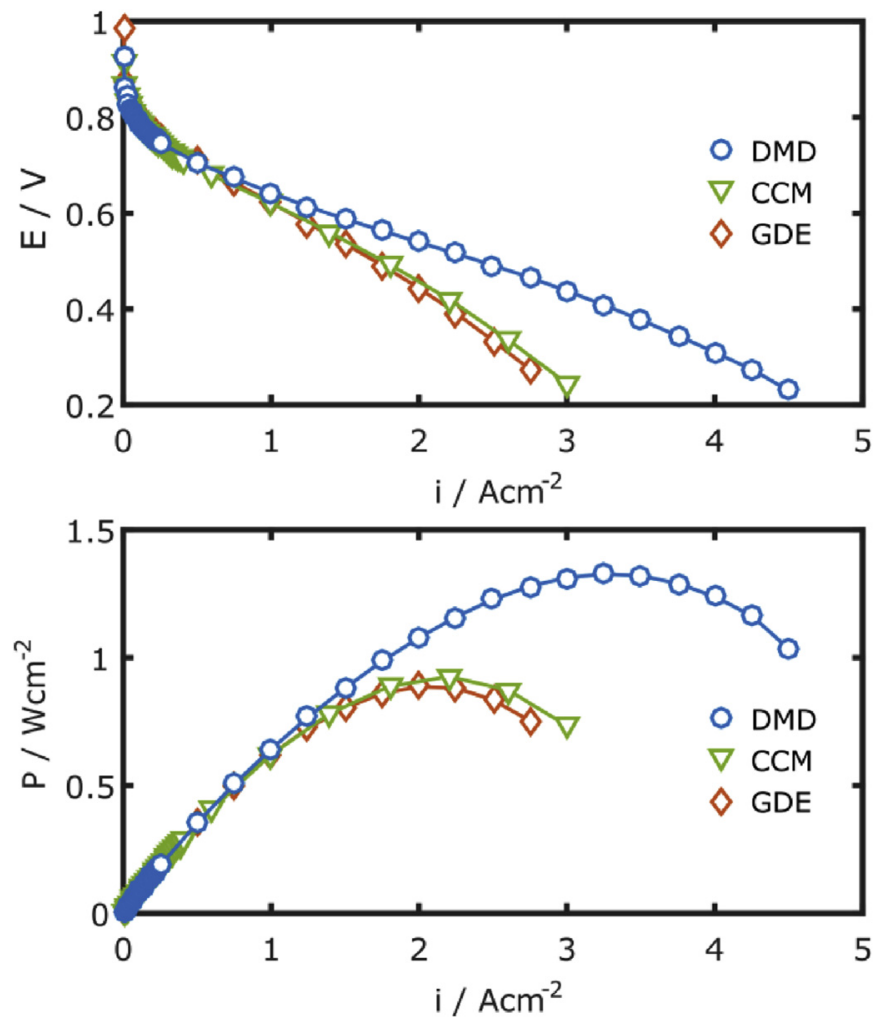

Fig. 7. Polarization data and power densities of the DMD, CCM and GDE fuel cells (reference membranes: Nafion NR-211). Operation conditions were: $\mathrm{H}_{2} / \mathrm{O}_{2}$ 0.25/0.5 l/ min fixed flow, $80{ }^{\circ} \mathrm{C}, 90 \% \mathrm{RH}$, ambient pressure, $0.1 \mathrm{mg} / \mathrm{cm}^{2}$ Pt-loading (anode/ cathode). 
improvement, while only $10 \%$ is caused by the reduced ionic resistances in this state of operation.

Furthermore, DMD fuel cells can be operated at significantly higher current densities due to the improved water management, as can be seen in Fig. 7. This finding is highly relevant to the development of cost-effective fuel cells, especially in fuel cells with low Pt-loading, where high current densities are desired to achieve high $\mathrm{kW} / \mathrm{g}$ Pt-utilization efficiencies [30]. While the CCM reference cell exhibits its maximum power density $\left(0.9 \mathrm{~W} / \mathrm{cm}^{2}\right)$ at $2.2 \mathrm{~A} \mathrm{~cm}^{-2}$ the DMD fuel cell increases in power density up to $3.2 \mathrm{~A} \mathrm{~cm}^{-2}$ leading to a maximum value of $1.3 \mathrm{~W} / \mathrm{cm}^{2}$. This again emphasizes the important role of improved water management to enable superior power densities with the DMD fuel cell.

\section{Conclusion}

In this work, the reasons for the high power density of fuel cells fabricated with direct membrane deposition (DMD) were identified and quantified. With the help of a thickness variation and impedance spectroscopy three reasons for the higher power were found: (1) The measured thickness $(12 \mu \mathrm{m})$ of the directly deposited membrane is significantly lower compared to that of commercially available membranes, resulting in lower membrane resistance. (2) The ionic contact resistance at the membrane|catalyst layer interface was found to be $40 \%$ lower $\left(10 \mathrm{~m} \Omega \mathrm{cm}^{2}\right)$ than that of the CCM references $\left(16 \mathrm{~m} \Omega \mathrm{cm}^{2}\right)$. Together, the reduced membrane thickness and the improved membrane|catalyst layer interface result in a reduction of $52 \%$ of the ionic resistances compared to a conventional CCM fuel cell with a Nafion NR-211 membrane. (3) EIS reveals that DMD reduces mass transport losses and therefore $R_{L F-H F}$ $\left(0.12 \Omega \mathrm{cm}^{2}\right)$ by a factor of 2.2 compared to a CCM fuel cell $\left(0.27 \Omega \mathrm{cm}^{2}\right)$ with NR-211 membrane operated at its maximum power density. The improved mass transport is believed to be caused by an increased water back-diffusion through the thin membrane, enabling higher oxygen diffusivity through the catalyst layer. Impedance spectroscopy revealed that the reduced mass transport resistance accounts for $90 \%$ of the improvement of the DMD compared to a CCM reference at its maximum power point. It is therefore the major reason for the increased power density of DMD fuel cell, while only $10 \%$ of the improvement is caused by the reduced ionic resistances as described above. Since the reduced membrane thickness has an impact on both resistances, this thickness reduction is therefore the most important improvement of the DMD fuel cell compared to fuel cells with conventional membranes.

\section{Acknowledgments}

This work was funded by the BMBF within the project "GECKO" (grant number 03SF0454C). S. Holdcroft would like to thank the Natural Sciences and Engineering Research Council of Canada (NSERC) for funding and 4D Labs for the use of its facilities. The authors would like to thank D. Gerteisen and R. HankeRauschenbach for valuable discussions and A. Hartmann for the assistance in sample fabrication. 


\section{Appendix A. Supplementary data}

Supplementary data related to this article can be found at http:// dx.doi.org/10.1016/j.jpowsour.2016.06.132.

\section{References}

[1] M. Klingele, M. Breitwieser, R. Zengerle, S. Thiele, J. Mater. Chem. A 3 (2015) $11239-11245$.

[2] M. Breitwieser, M. Klingele, B. Britton, S. Holdcroft, R. Zengerle, S. Thiele, Electrochem. Commun. 60 (2015) 168-171.

[3] N. Wehkamp, M. Breitwieser, A. Büchler, M. Klingele, R. Zengerle, S. Thiele, RSC Adv. 6 (2016) 24261-24266.

[4] A.Z. Weber, R.L. Borup, R.M. Darling, P.K. Das, T.J. Dursch, W. Gu, D. Harvey, A. Kusoglu, S. Litster, M.M. Mench, R. Mukundan, J.P. Owejan, J.G. Pharoah, M. Secannel, I.V. Zenyuk, J. Electrochem. Soc. 161 (2014) F1254.

[5] W. Albery, C. Elliott, A.R. Mount, J. Electroanal. Chem. Interfacial Electrochem. 288 (1990) 15-34.

[6] M.C. Lefebvre, R.B. Martin, P.G. Pickup, Electrochem. Solid-State Lett. 2 (1999) 259-261.

[7] H.H. Wang, X.-Z. Yuan, H. Li, PEM Fuel Cell Diagnostic Tools, CRC Press/Taylor \& Francis, Boca Raton, FL, 2012.

[8] Seyed Mohammad Rezaei Niya, M. Hoorfar, J. Power Sour. 240 (2013) $281-293$.

[9] T.E. Springer, T.A. Zawodzinski, M.S. Wilson, S. Gottesfeld, J. Electrochem. Soc 587 (1996).

[10] R.N. Carter, S.S. Kocha, F. Wagner, M. Fay, H.A. Gasteiger, ECS Trans. 11 (2007) 403-410.

[11] J. Peron, A. Mani, X. Zhao, D. Edwards, M. Adachi, T. Soboleva, Z. Shi, Z. Xie T. Navessin, S. Holdcroft, J. Membr. Sci. 356 (2010) 44-51.

[12] F.N. Buchi, G.G. Scherer, J. Electrochem. Soc. 148 (2001) A183-A188.

[13] R. Jiang, C.K. Mittelsteadt, C.S. Gittleman, B1440, J. Electrochem. Soc. 156 (2009).

[14] K.R. Cooper, J. Electrochem. Soc. 157 (2010) B1731.

[15] B.S. Pivovar, Y.S. Kim, J. Electrochem. Soc. 154 (2007) B739.

[16] Y. Liu, M. Murphy, D. Baker, W. Gu, C. Ji, J. Jorne, H.A. Gasteiger, ECS Trans. 11 (2007) 473-484.

[17] R. Makharia, M.F. Mathias, D.R. Baker, J. Electrochem. Soc. 152 (2005) A970.

[18] X. Yuan, H. Wang, J. Colinsun, J. Zhang, Int. J. Hydrogen Energy 32 (2007) $4365-4380$

[19] K.R. Cooper, V. Ramani, J.M. Fenton, H.R. Kunz, Experimental Methods and Data Analyses for Polymer Electrolyte Fuel Cells, 2005. Southern Pines, NC.

[20] F. Barbir, PEM Fuel Cells: Theory and Practice, second ed., Elsevier Science, San Diego, 2012.

[21] T.J. Freire, E.R. Gonzalez, J. Electroanal. Chem. 503 (2001) 57-68.

[22] V. Paganin, C. Oliveira, E. Ticianelli, T. Springer, E. Gonzalez, Electrochim. Acta 43 (1998) 3761-3766.

[23] H. Li, Y. Tang, Z. Wang, Z. Shi, S. Wu, D. Song, J. Zhang, K. Fatih, J. Zhang, H. Wang, Z. Liu, R. Abouatallah, A. Mazza, J. Power Sour. 178 (2008) 103-117.

[24] H.H. Voss, D.P. Wilkinson, P.G. Pickup, M.C. Johnson, V. Basura, Electrochim Acta 40 (1995) 321-328.

[25] B. Andreaus, A.J. McEvoy, G.G. Scherer, Electrochim. Acta 47 (2002) 2223-2229.

[26] M. Adachi, T. Navessin, Z. Xie, B. Frisken, S. Holdcroft, J. Electrochem. Soc. 156 (2009) B782.

[27] M. Adachi, T. Navessin, Z. Xie, F.H. Li, S. Tanaka, S. Holdcroft, J. Membr. Sci. 364 (2010) 183-193.

[28] M. Breitwieser, R. Moroni, J. Schock, M. Schulz, B. Schillinger, F. Pfeiffer, R. Zengerle, S. Thiele, Water management in novel direct membrane deposition fuel cells under low humidification, Int. J. Hydrogen Energy 41 (26) (13 July 2016) 11412-11417. ISSN 0360-3199 http://dx.doi.org/10.1016/j. ijhydene.2016.05.018.

[29] Y. Jeon, D.J. Kim, J.K. Koh, Y. Ji, J.H. Kim, Y.-G. Shul, Sci. Rep. 5 (2015) 16394.

[30] A. Ohma, T. Mashio, K. Sato, H. Iden, Y. Ono, K. Sakai, K. Akizuki, S. Takaichi, K. Shinohara, Electrochim. Acta 56 (2011) 10832-10841. 